\title{
SURVEYING A LANDSLIDE IN A ROAD EMBANKMENT USING UNMANNED AERIAL VEHICLE PHOTOGRAMMETRY
}

\author{
F. Carvajal ${ }^{\text {a, } *, \text { F. Agüera }}{ }^{\text {a }}$, M. Pérez ${ }^{\text {a }}$ \\ ${ }^{a}$ ESI - Dept. of Rural Engineering, University of Almeria, Crta. Sacramento sn, 04120 Almeria, SPAIN \\ carvajal@ual.es
}

Commission I, WG I/V

KEY WORDS: UAV Photogrammetry, Landslide, Road Embankment

\begin{abstract}
:
Most of the works of civil engineering, and some others applications, need to be designed using a basic cartography with a suitable scale to the accuracy and extension of the plot.

The Unmanned Aerial Vehicle (UAV) Photogrammetry covers the gap between classical manned aerial photogrammetry and handmade surveying techniques because it works in the close-range domain, combining aerial and terrestrial photogrammetry, but also introduces low-cost alternatives.

The aim of this work is developing of an accurate and low-cost method to characterize landslides located on the size of a road. It was applied at the kilometric point 339 belonging to the A92 dual carriageway, in the Abla municipal term, province of Almeria, Spain. A photogrammetric project was carried out from a set of images taken from an md4-200 Microdrones with an on-board calibrated camera 12 Megapixels Pentax Optio A40. The flight was previously planned to cover the whole extension of the embankment with three passes composed of 18 photos each one. All the images were taken with the vertical axe and it was registered $85 \%$ and $60 \%$ longitudinal and transversal overlaps respectively.

The accuracy of the products, with planimetric and altimetric errors of 0.049 and $0.108 \mathrm{~m}$ repectively, lets to take measurements of the landslide and projecting preventive and palliative actuations.
\end{abstract}

\section{INTRODUCTION}

Most of the works of civil engineering, and some others applications, need to be done using basic cartography with a suitable scale to the accuracy and extension of the plot (Cerdà, 2007; Ohnishia et al., 2006; Chiabrando et al., 2011)

The methods to calculate the stability of the landslides can be classified in numerical methods and limit equilibrium methods (Ayala and Posse, 1986). The first group is based on the static laws and the terrain deformations. In the practise, the use is complex and they require the application of finite elements compute methods. The second group is based exclusively on the static laws. Some of the most used are Morgenstern-Price, Spencer and Bishop Rigorous Method. All of that have a relatively easy practical application but the assumed simplification respect to the terrain deformations sometime is not acceptable.

Both sets, numerical and the limit equilibrium methods, require having an accurate landslide geometric representation, especially if the algorithms are applied with specific software.

In the case of some landscapes located in the side of the roads due to instability of materials, it is often some hundreds of meters. Conventional photogrammetry from manned aerial platforms do not reach the needed accuracy level because it flying height. By other hand, surveying carried out with total stations, theodolites, level stations or GPS can be unviable when the landscape is inaccessible, and too expensive because the needed manpower.

In the last decade, a new alternative which covers the gap between both techniques was developed. The Unmanned Aerial Vehicle (UAV) Photogrammetry describes photogrametric measurement platforms, which operates as either remotely controlled, semi-autonomously or autonomously, all without pilot sitting in the platform. It works in the close-range domain, combining aerial and terrestrial photogrammetry, but also introduces low-cost alternatives to the classical manned aerial photogrammetry (Eisenbeis, 2009).

The aim of this work was developing and application of an accurate and low-cost method to characterize landslides located on the size of a dual carriageway.

\section{MATERIALS AND METHODS}

The landslide geometric characterization was carried out following two steps.

\subsection{Outdoor campaign}

The UAV used in this work was md4-200 model by Microdrones (Microdrones $\mathrm{GmbH}, 2011$ ), a 4-rotor vertical take-off and landing vehicle with autonomous and semiautonomous control capacities (see fig. 1).

\footnotetext{
* Corresponding author.
} 


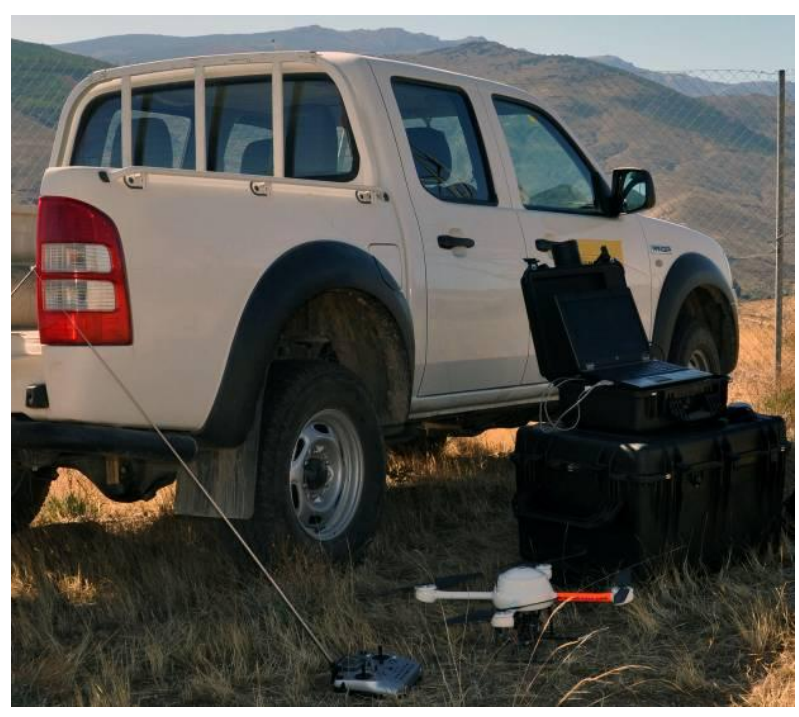

Figure 1. Microdrone UAV, base station and hand held remote control transmitter

It is equipped with GPS antenna, altimeter and magnetometer to calculate the position coordinates during the flight. Several signals from the navigation tools (accelerometers, gyroscopes, airpressure, humidity and temperature sensors, etc) are emmited to base station by radio transmitter and are saved on the onboard flight recorder (microSD card) wich permits a postflight analysis.

Furthermore, a digital camera Pentax Optio A40, with 12 megapixels, photo stabilization, trigger, zoom function and tilt camera mount controlled from the remote control (see fig. 2).

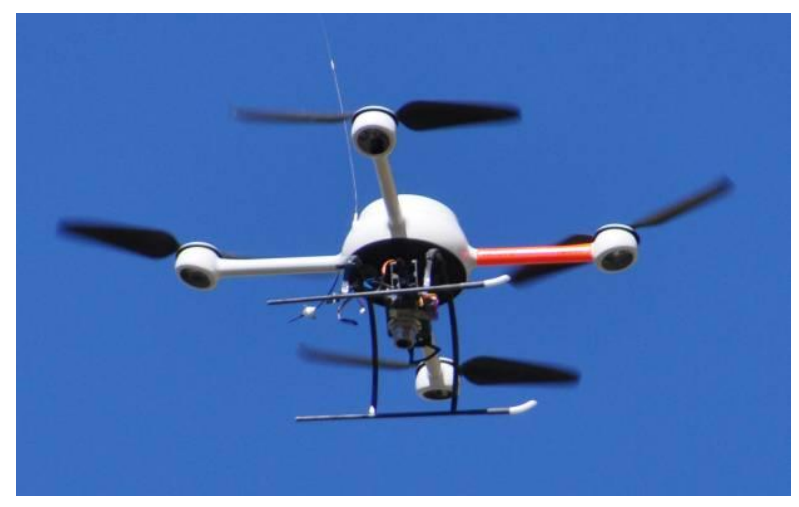

Figure 2. On-board digital camera Pentax Optio A40

Thanks to the waypoint navigation guidance the drone can be operated fully autonomous including auto start and auto landing. The flight route is programmed using a graphical interface based on Google Earth information, and the actions to do in each waypoint are defined, including holding position, photo orientation and trigger activation.

The studied landslide is on the embankment belonging to the A92, a dual carriageway located between Almeria and Granada provinces, southeast Spain. The embankment is around $100 \mathrm{~m}$ long, and the elevation differences between the ditch and the top of the embankment is $20 \mathrm{~m}$ (see fig. 3).

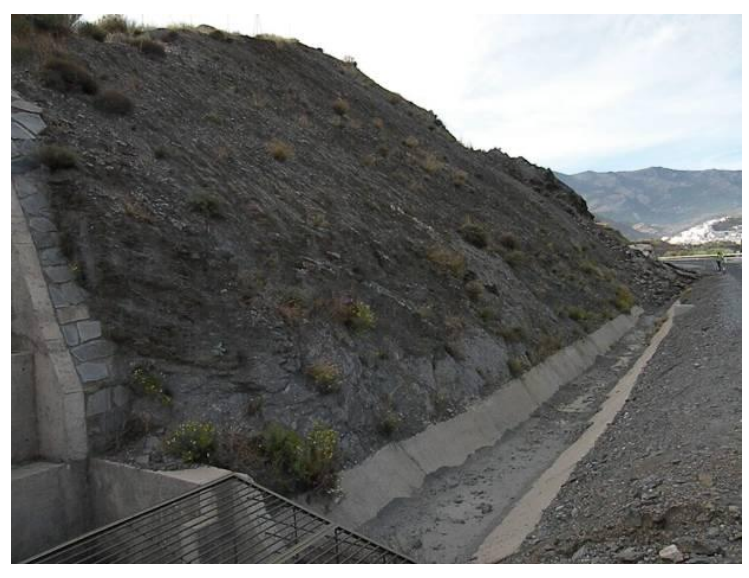

Figure 3. Embankment in the kilometric point 339 belonging to the A92 dual carriageway, Spain

The kilometric point 339 is in the Abla municipal term, and as it can observe in fig. 4, the instability of the material was evidenced some time ago due the installed contention wall made of stones.

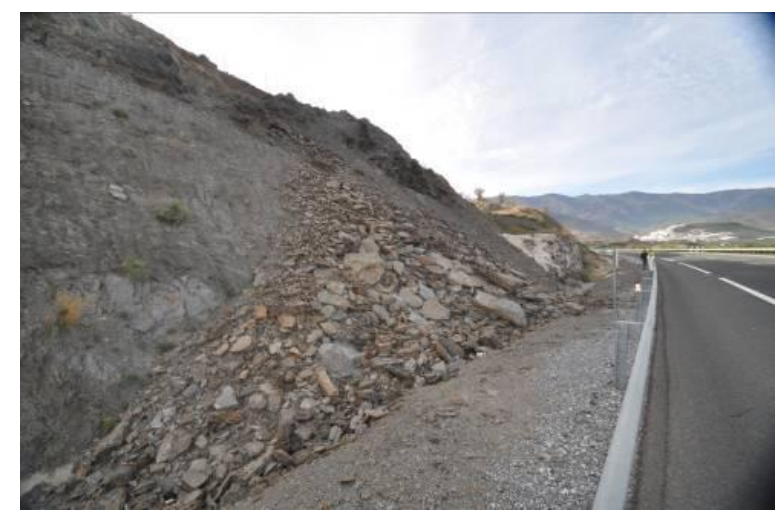

Figure 4. Landslide detail with the contention wall in the second plane of the image

Using the Md-Cockpit V2100.7.5.9 compatible software with the drone, module Waypoint Editor, the flight planning was designed. Three parallel routes along the curved trace of the road, including 18 photos each one, make up the total flight planning. The longitudinal and transversal overlaps, $85 \%$ and $60 \%$ respectively, were enough to cover the entire target area (see fig. 5).

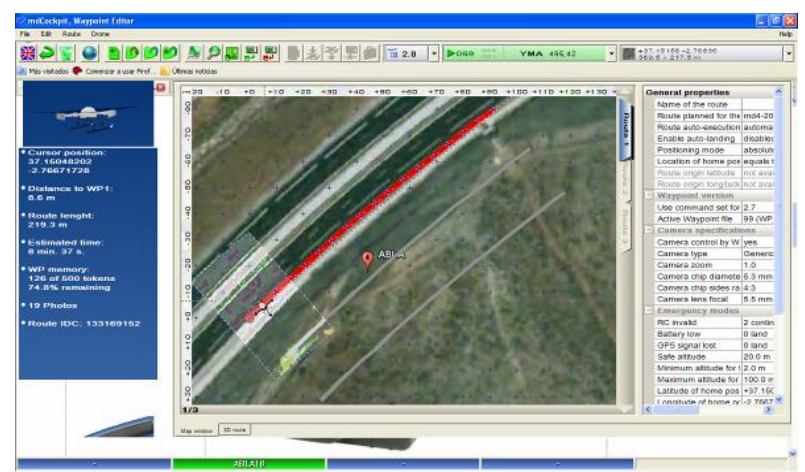

Figure 5. Flight planning make up three parallel routes 
Photos were taken at $50 \mathrm{~m}$ high from the road level and each of them covers $43 \times 28 \mathrm{~m}$ approximately.

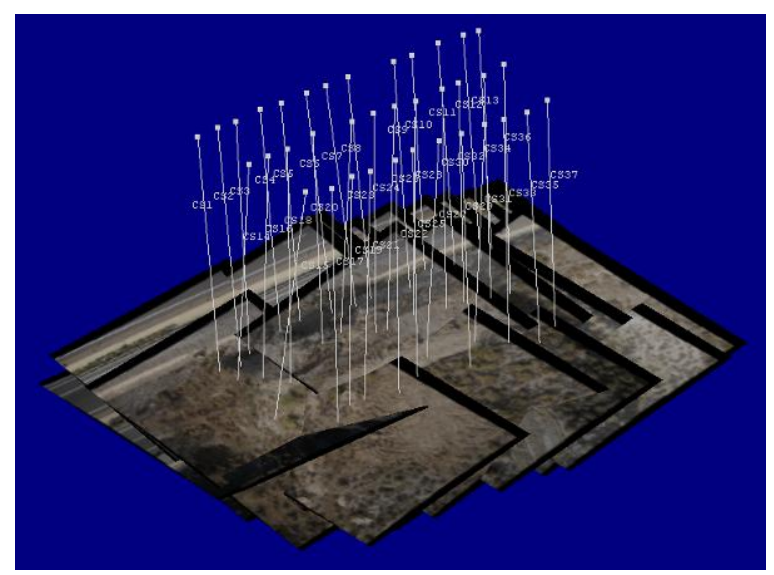

Figure 6. Mosaic of the project photos and points where the photos were taken from

At the moment in which the flight was done, the average wind velocity was $3.5 \mathrm{~m} / \mathrm{s}$. The wind effects can be observed in fig. 6 , where the deviations of the linear path are shown.

\subsection{Photogrammetric project}

Photomodeler Scan 2011 (Photomodeler, 2011) was the chosen software to photogrammetric processes. It is a low-cost multiapplication software which can be used with both, convergent and parallel photogrammetric projects (Eisenbeis, 2009).

Geometric errors introduced by the camera lens were previously calibrated using the field calibration method based on a previous lab calibration. The calibration project was carried out using several target points with known coordinates located $50 \mathrm{~m}$ away from the camera position, the same flight high which was used in the outdoor work.

The calibrated parameters were focal length, format size of the CCD camera sensor, location of the principal point sensor, two radial distortion function coefficients and two decentring distortion function coefficients (Wolf, 1983) (see tab. 1).

\begin{tabular}{|l|l|l|}
\hline Focal length (mm) & 8.1841 \\
\hline Format size (micro-m) & $7.4853 \times 5.6132$ \\
\hline Principal point (micro-m) & $3.7223,2.6773$ \\
\hline $\begin{array}{l}\text { Radial distortion function } \\
\text { parameters }\end{array}$ & $\mathrm{K} 1$ & $2.820 \mathrm{e}-003$ \\
\cline { 2 - 3 } & $\mathrm{K} 2$ & $-1.526 \mathrm{e}-005$ \\
\hline $\begin{array}{l}\text { Decentring distortion } \\
\text { function parameters }\end{array}$ & $\mathrm{P} 1$ & $5.139 \mathrm{e}-005$ \\
\cline { 2 - 3 } & $\mathrm{P} 2$ & $-4.462 \mathrm{e}-004$ \\
\hline
\end{tabular}

Table 1. Pentax Optio A40 calibration report

All photos of the photogrammetric project were resampled using the distortion functions obtained with the pre-calibration.
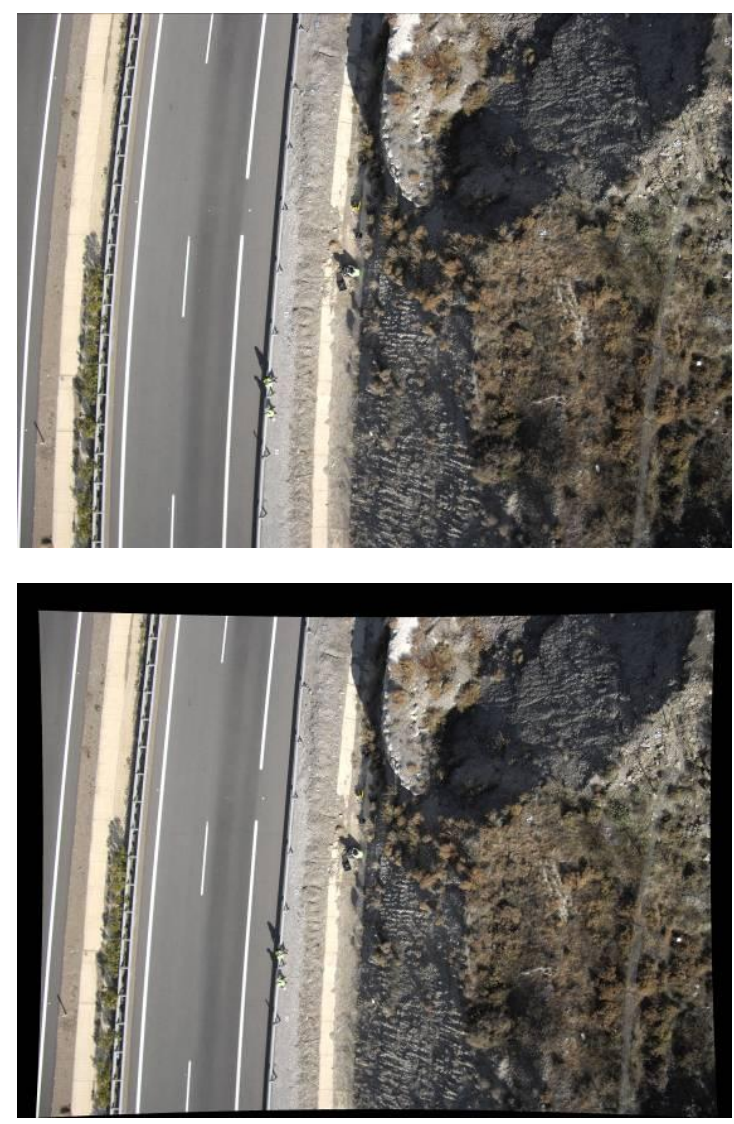

Figure 7. Upper image is one of the original photos taken on the outdoor work. The lower one is the same photo after distortion error correction

Fig. 7 shows how the straight lines of the road are rectified after distortion correction process. The relative orientation process (Wolf, 1983) was carried out, identifying sets of common points in each overlapped pairs of photos, known as tie points. A total amount of 8451 tie points were automatically identified at the relative orientation process, using only 37 of the 54 project photos, which were enough to cover the entire target surface. It was selected the main 41 overlaps between them.

The relative orientation is carried out using an iterative method which calculates an overall error estimator of the block adjustment, and the root squared mean error (RMS) of each tie point used. After the fourth iteration, the system was converged. The overall error was 0.607 pixels, and maximum RMS was 0.832 pixels.

The absolute orientation process (Wolf, 1983) was applied by the affine transformation approach which implies translation, rotation and scale changing, using the three best coordinates selected from a data set of ground control points. The photogrammetric block was fit to the Universal Transverse Mercator UTM coordinate system, northern hemisphere and zone number 30, with the European Datum 1950 and the geoidal model Ibergeo.

\section{RESULTS}

Once the photogrammetric block was adjusted and projected to the UTM system, three-dimensional point clouds were detected in all over the model (fig. 8). After edition and noise filtering, a triangulated surface with 147914 triangles was derived from 77306 mesh points through the plot. 


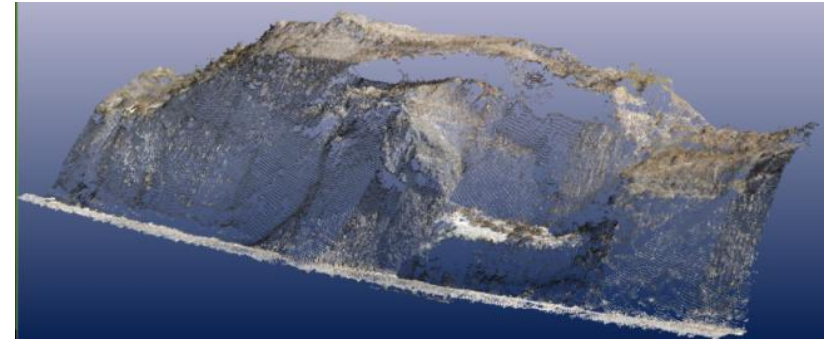

Figure 8. Point mesh obtained from the photogrammetric model

Table 2 shows the main univariate statistics of the obtained data set. It can be observed that the autocorrelation algorithm delivers a well distributed point cloud which position is adjusted to a normal distribution.

\begin{tabular}{|l|c|c|c|}
\hline & $\mathrm{X}$ & $\mathrm{Y}$ & $\mathrm{Z}$ \\
\hline Minimum: & 520801.76 & 4111763.76 & 807.14 \\
\hline 25\%-tile: & 520858.04 & 4111797.75 & 811.43 \\
\hline Median: & 520878.13 & 4111818.40 & 818.25 \\
\hline 75\%-tile: & 520899.95 & 4111836.29 & 822.72 \\
\hline Maximum: & 520944.18 & 4111880.36 & 830.42 \\
\hline Range: & 142.41 & 116.59 & 23.28 \\
\hline Mean: & 520878.60 & 4111817.50 & 817.81 \\
\hline $\begin{array}{l}\text { Standard } \\
\text { Deviation: }\end{array}$ & 27.96 & 24.38 & 6.08 \\
\hline Variance: & 781.96 & 594.83 & 37.08 \\
\hline Coef. of Variation: & \multicolumn{2}{|c|}{0.0074} \\
\hline Coef. of Skewness: & -0.0094 \\
\hline
\end{tabular}

Table 2. Univariate Statistics of the resulting data set

A 55804 triangles surface was generated using the threedimensional points (fig. 9). It can be observed that there no texture to certain zones, coloured with flat grey tone, which were almost parallel to the photos' axes, that is, vertical planes.

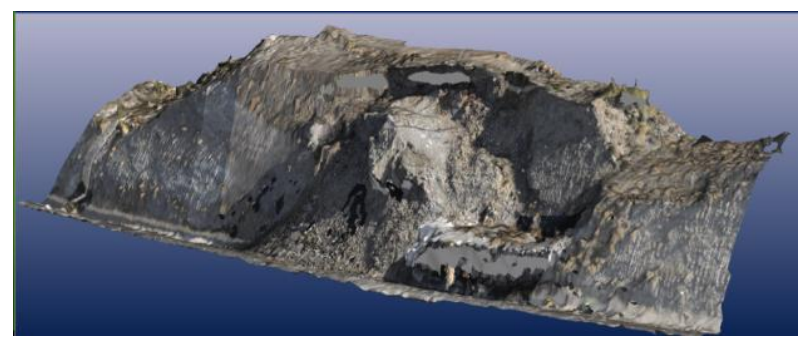

Figure 9. Triangle surface represented by high-quality texture mode

Because of the irregular concentration on the triangle surface points, a new surface, known as Digital Elevation Model (DEM) was interpoled (fig. 10), using a regular grid scheme, obtaining one point each $0.5 \mathrm{~m}$ interpolated by the radial basis function method (Wolf, 1983; Webster and Oliver, 1990).

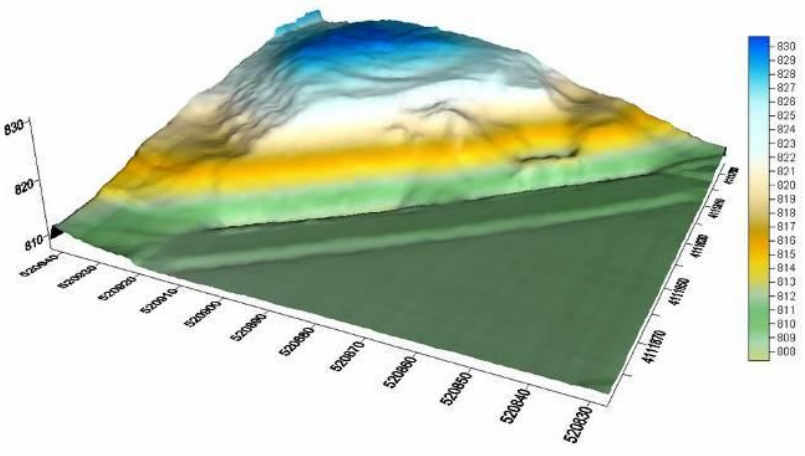

Figure 10. Digital Elevation Model interpolated with a 10-cm grid

Contours lines were obtained by intersection of the DEM and a set of 1-m interval parallel planes to the horizontal plane, and the information was exported to the $\mathrm{dxf}$ format (fig. 11).

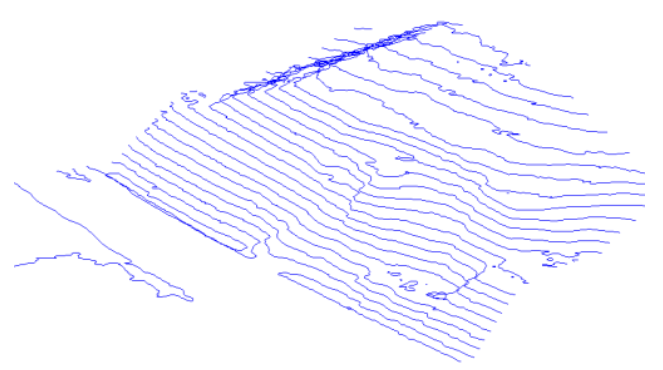

Figure 11. Perspective view of the 3D contours lines with $1 \mathrm{~m}$ interval

Another typical product from the photogrammetric projects is the ortho-image, with cartographic properties, obtained by resampling of the project photos accounting the topographic deformations. The DEM and the photogrammetric block adjusted ware the input data to orthorectification process. Fig, 12 shows the contour lines over the $0.01-\mathrm{m}$ pixel ortho-image.

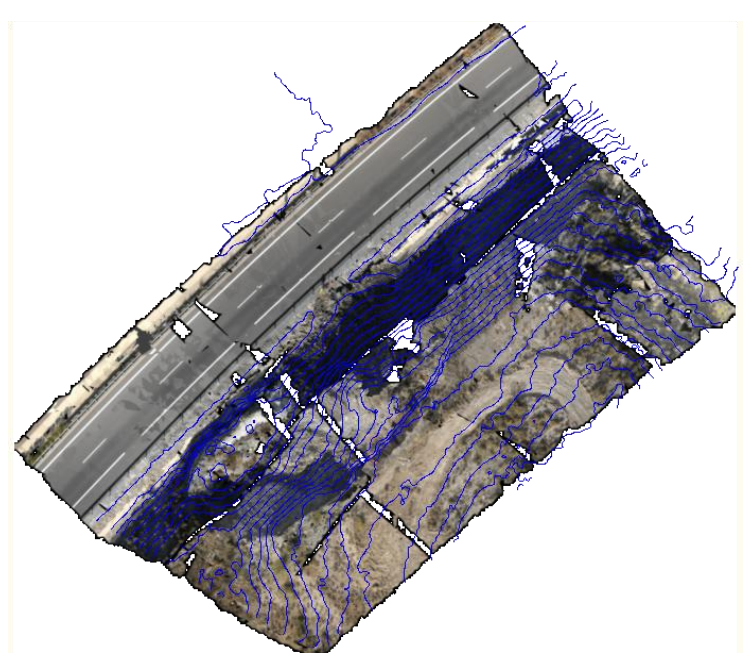

Figure 12. 0.01-m Ortho-image of the photogrammetric project with the contour lines superimposed 
Thanks to 31 target points distributed through the area of study, the overall accuracy of the project was calculated based on the observed-estimated coordinates comparison. The observed data set included the measured coordinates of the 31 check points, which were materialized by some printed coded target (fig. 13).

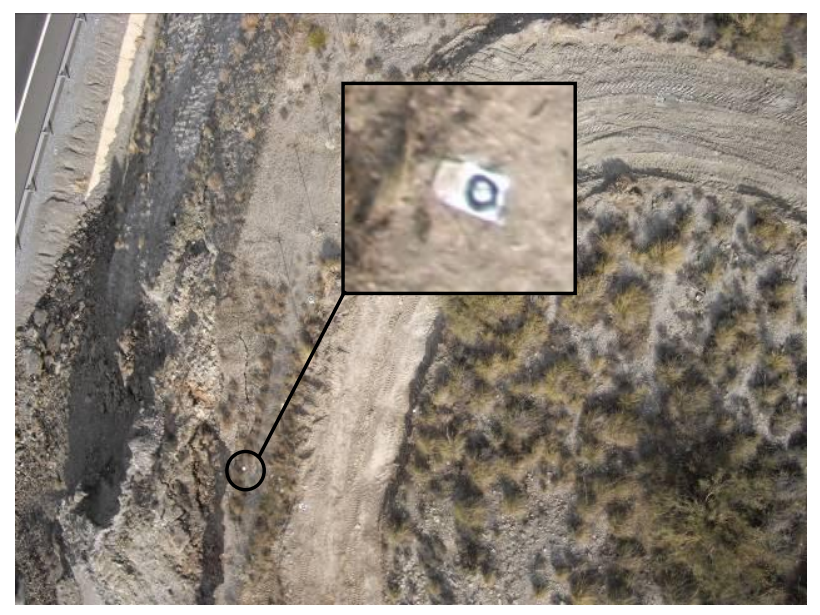

Figure 13. Detail of one of the 29 target points zoomed from a photo of the photogrammetric project

They were well distributed all over the studied area trying that photos obtained from the drone include them (fig. 14).

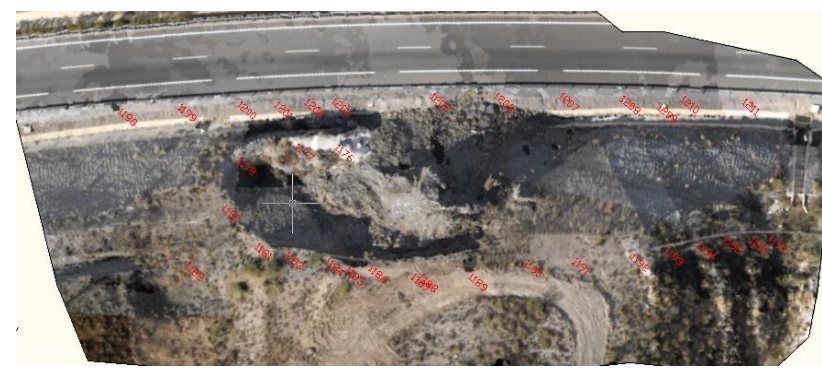

Figure 14. Location of the 31 target points used as check points for the error estimation

The coordinates of the target points were measured with a Trimble R6 GPS Receiver (Trimble, 2011) in Real Time Kinematic Mode (RTK), applying a post-process with the time data corrections saved on the Calar Alto station, belonging to Positioning Andalusian Network (RAP) (Red Andaluza de Posicionamiento, 2011), $20.8 \mathrm{Km}$ far away from the studied area, at the same time of the topographic campaign.

Comparing the measured with GPS X and Y coordinates of the 31 check points and its positions over the orthoimage, the planimetric root mean squared error $\left(\mathrm{RMS}_{\mathrm{XY}}\right)$ was obtained (tab. 3). The altimetric root mean squared error $\left(\mathrm{RMS}_{\mathrm{Z}}\right)$ was obtained by comparing the measured with GPS $\mathrm{Z}$ coordinates of the check points, and the estimated from the DEM at the positions measured with GPS.

A previous study, applying the Kolmogorov-Smirnov text (Royston, 1982), showed that the X, Y and Z committed errors are distributed as normal functions at a confidence level of $99 \%$.

\begin{tabular}{|c|c|c|}
\hline $\begin{array}{c}\text { EmaxX } \\
(\mathrm{m})\end{array}$ & $\begin{array}{c}\text { EmaxY } \\
(\mathrm{m})\end{array}$ & $\begin{array}{c}\text { EmaxZ } \\
(\mathrm{m})\end{array}$ \\
\hline 0.097 & 0,055 & 0,234 \\
\hline $\begin{array}{c}\mathrm{RMS}_{\mathrm{xy}} \\
(\mathrm{m})\end{array}$ & $\begin{array}{c}\mathrm{RMS}_{\mathrm{z}} \\
(\mathrm{m})\end{array}$ & $\begin{array}{c}\mathrm{RMS}_{\text {total }} \\
(\mathrm{m})\end{array}$ \\
\hline 0.049 & 0.108 & 0.119 \\
\hline
\end{tabular}

Table 3. Accuracy test estimating the errors committed in all the steps of the application

\section{CONCLUSIONS}

It can be concluded that the total error committed, up to $0.12 \mathrm{~m}$, is enough to geometric characterization of landslides in road embankment.

Both obtained products, DEM and ortho-photos can be used as inlet data to some of the more used methods to calculate the stability of the landslides, as numerical methods and limit equilibrium methods.

UAV Photogrammetry shows as an efficient method located between the classical aerial photogrammetry and terrestrial surveying techniques.

It has to be adverted that the methodology was limited by the meteorological conditions, specially the wind speed which has to be up to $5 \mathrm{~m} / \mathrm{s}$.

Furthermore, the direction of the taken images, orthogonal to the road plane, doesn't is the best point of view to characterize some of the landslide surfaces. Some of these surfaces were hidden because the main landslide angle is close to $45^{\circ}$ with respect to the horizontal plane.

The accessibility of the embankment to the ground control points measurement can be difficult and dangerous, especially when the topography is strong or the increment between the top and the bottom of the embankment is high.

For the future works it will be test the application of photogrammetric projects with parallel axis photos, oriented to the main slope of the embankment.

Furthermore, it will be quantified the increase of the total error when the well distributed ground control points are deliberated omitted.

\section{REFERENCES}

Ayala, F.J., Posse, A., 1986. Manual de ingeniería de taludes. Instituto Geológico y Minero de España.

Cerdà, A. 2007. Soil water erosion on road embankments in eastern Spain. Science of the Total Environment, 378 pp. 151155.

Chiabrando, F., Nex, F., Piatti, D., Rinaudo, F., 2011. UAV and $R P V$ systems for photogrammetric surveys in archaelogical areas: two tests in the Piedmont region (Italy). Journal of Archaeological Science 38, pp 697-710.

D.G. Krige. A statistical approach to some mine valuations and allied problems on the Witwatersrant. Master's Thesis (inedited) 1951.

Eisenbeis, H., 2009. UAV Photogrammetry. Institut für Geodäsie und Photogrammetrie, Zürich. 
Microdrones GmbH. 2011. Comercial website http://www.microdrones.com/en_home.php (accessed $20 \mathrm{Jul}$. 2011).

Ohnishia, Y., Nishiyamaa, S., Yanoa, T., Matsuyamab, H., Amano, K., 2006. A study of the application of digital photogrammetry to slope monitoring systems. International Journal of Rock Mechanics \& Mining Sciences 43 pp 756-766.

Photomodeler software website. 2011. Mesauring and Modeling the Real World. http://www.photomodeler.com/ (accessed 20 Jul. 2011).

Red Andaluza de Posicionamiento (RAP) website. 2011. http://www.juntadeandalucia.es/obraspublicasytransportes/reda ndaluzadeposicionamiento/rap/ (accessed 20 Jul. 2011).

Royston J.P. 1982. Expected normal order statistics (exact and aproximate). Applied Statistic 31: 161-165.

Trimble website. 2011. http://www.trimble.com/ (accessed 20 Jul. 2011).

Webster, R., Oliver, M.A., 1990. Statistical methods in soil and land resource sourvey. Oxford University Press.

Wolf., P.R. 1983. Elements of photogrammetry. Mc. Graw Hill.

\section{ACKNOWLEDGEMENTS}

This work was supported by grant P08-TEP-3870 from CICEJunta de Andalucía (Spain), co-financed with FEDER funds of the European Union. 